I have, however, taken orono here, as Mr. Strecker wrote me that there was a specimen of it in a box of Lepidoptera that I sent to him in 1872 . It is very rare, as I have not met with it since.

\title{
HE'TFROCERA.
}

SPHINGIDE.

Lethic gordius Cram.

One example; Mr. Pearson.

ZYGAFIDIS.

Aiypia Macullochii Kirby.

Two examples ; Mr. Knetzing.

\section{DEAR SIR,--}

\section{CORREPSONUENCE}

In the October No. I nind an account of Mr. Dimmocks method of denuding the wings of Lepidoptera. From the account given, it seems to me that it will take as much time, though perhaps less trouble, than the old way of denuding them with a moistened brush. It may, however, answer for butterflies and the larger moths, but for Tineidæ, Tortricidæ, Pyralidæ, and the smaller moths generally, the plan of which I have given an account in a previous volume of this magazine seems to me preferable. It is as follows: Take a piece of glass about one inch by three in size (say a glass "slide" of a microscope), place the wing on it, in from one to three or four drops of strong solution of potash, according to the size of the wing; cover with one of the thin pieces of covering glass of microscopists (do not use enough fluid to float the cover ylass) ; hold, with a clothes pin or other small forceps, the large glass over a lamp chimney until it begins to boil, removing it at the first sign of ebulition, when the wing will be found denuded if it is a fresh and small specimen; if large, or old and dry, a little longer boiling may be necessary. The fluid may then be drained off by tilting the glass a little, and all traces of the potash removed by adding a few drops of water; and the cover gluss being removed, the wing may be mounted on the same glass or floated on to another, or it may be at once accurately sketched by the microscope and 
camera lacida. The whole process of mounting may be accomplished in a minute or little more, or it may be mounted and sketched in five minutes or less. In this way I have nounted and sketched hundreds of wings of Tineidx, which $I$ hope some day to publish in the pages of the Can. Ent.

V. 'T. Champies.

Colorado Springs, Coloradu, Feb., 1876 .

NNTOMOLOGICAJ, NOTES.

DEAR SIR,- -

Ceratomia quadricomis. - I have during the past season, and for the first time in my life, taken a number of the larva of Ceratomia quadriconis Harr., of a brown color. Out of live taken in one locality, four were of a deep brown. The fifth was of the usual green hue. These larve were about half grown when captured. This was early in September, but since then I have taken several other specimens, the majority of which were brown. I should like to learn whether any of your readers have, at any time, made similar captures.

Doryphora ro-lineata.-A safe and effective method of destroying this beetle is to drag an ordinary butterfy net over the haulm when the larva and beetles are feeding. By this method, and without making any particular effort, I captured on Long Island, this year, over five hundred specimens in about as many minutes. By making a sort of drag net, large enough to be worked by two boys, a nuch larger number could of course be captured in a given time. I have no doubt that Long Island will be plentifully supplied with Io-lincata next year; for, although thousands were drowned and washed up on the beach at Coney Island and elsewhere, the number that escaped must have been great. But, although admitting the desirability of ridding ourselves of this pest, I by no means admit that it is the scourge talked about by some Entomologists. As I intimated before, we had plenty of them on this Island, but no one complains of a small crop of potatoes in consequence.

W. V. ANDREWS.

36 Bœrtum Place, Brooklyn.

ERRATA. - On page 16 , line 7 from top, for Heliophila renipuncter read H. unipuncta. 